MATEC Web of Conferences 1, 00002 (2012)

DOI: $10.1051 /$ matecconf $/ 20120100002$

(C) Owned by the authors, published by EDP Sciences, 2012

\title{
Finite element modeling of the aluminothermic welding with internal defects and experimental analysis
}

\author{
I. Mouallif ${ }^{1}$, Z. Mouallif ${ }^{2}$, A. Benali $^{1}$, and F. Sidki ${ }^{1}$ \\ ${ }^{1}$ Laboratory of Control and Mechanical Characterization of Materials and of Structures, ENSEM, BP 8118 Oasis, Hassan II \\ University, Casablanca, Morocco \\ ${ }^{2}$ Mathematics Department, FST, BP 577, Hassan I University, Settat, Morocco
}

\begin{abstract}
There are several hundreds aluminothermic welds and tenth of new welds being made daily on the Moroccan rail network. Although the aluminothermic welding technique is well proven, it is a critical safety component of the rail infrastructure. The consequences of a single failure could result in the derailment. The observations suggest that these defects are mainly of two types: defects of adhesion (or bonding defects) and porosity defects (or multiple blisters defects). Each of these defects may constitute a privileged site of stress concentration. Depending on the level of these stresses, potential damage process may be developed and put off the rail. It therefore seems necessary to model the mechanical behavior of these welds with these defects in order to classify them by their criticality. In this study, we therefore modeled with the same load and with the same boundary conditions, the weld seam for each type of defect. The numerical and experimental results show that the defects of adhesion tend to concentrate the most constraints.
\end{abstract}

\section{Introduction}

The increase in speed and trains frequency and to reduce vibrations, rails junction of railways is designed so as to obtain the continuity of the raceway. In general the rails connection is achieved by two processes:

- Resistance welding;

- Thermite welding.

This second method is the most common currently in the railways [1]. However, it was found that the damage of rails occurs most often in welded zones, which can have serious consequences on the safety and comfort during operation [2-3].

Indeed, during the derailment of the train 5941 between Andelat and Saint Flour (France) February $25^{\text {th }} 2006$, the LCPC (Laboratoire Central des Ponts et Chaussées) and the Centre of Expertise of SNCF have called into question: "... The default presented as a primer is located in the weld metal outside the fusion zone of the rail (bonding zone between the filler metal and the rail)....The rail break is related to material fragility and the presence of singular points created by the aluminothermic welding. The small bubble observed in the filler metal is one of the features that could initiate brittle fracture of the rail ... "[4].

In order to better understand this phenomenon, a thermite weld model containing volume defects (defects of porosity or multiple blisters) and planar defects (defects of adhesion or bonding) was proposed in this paper.

These defects that we observed from samples broken welds, are positioned in the weld zone. This modeling is done by considering different forms. A spherical shape for the porosity defect and adhesion defect is represented by an empty space in the rail/weld interface. Stresses were analyzed in the immediate vicinity of these defects, calculations are done using the finite element method with the code ANSYS. The local embrittlement phenomenon was shown by SEM in the vicinity of the adhesion defect.

\section{Problematic}

From the observations, we were able to classify the defects generated by the aluminothermic welding process following two types: adhesion defect (Figure 1a) and porosity defect (Figure 1b).

\subsection{Defect of adhesion}

The defect of adhesion (or bonding defect) is a major flaw in the Moroccan railways. This defect generates $75 \%$ of transverse fractures at the interface rail/weld (this was confirmed by ONCF "Office National des Chemins de Fer Marocain") and could be cause by a failure to preheat. 


\subsection{Defect of porosity}

At the time of the execution of an aluminothermic rail weld, the imprisonment of gas during the weld solidification generates a defect on the filler metal, called the defect of porosity (or multiple blisters) (figure 1b).

(a)
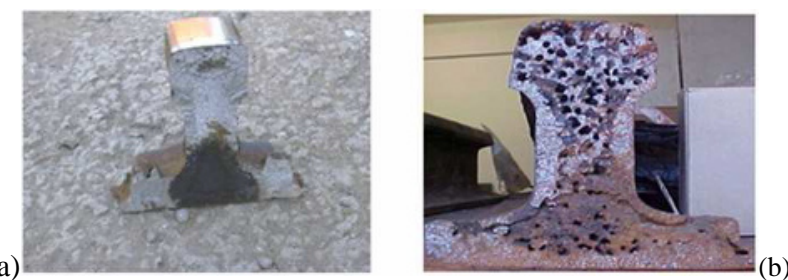

Fig. 1. (a) Defect of adhesion (or defect of bonding) and (b) defect of porosity

\section{Modeling of thermite weld defects}

In this section, a locomotive of 21.120 tons (2640 $\mathrm{kg} /$ wheel) was considered. The contact surface $\left(\mathrm{S}=51.26 \mathrm{~mm}^{2}\right)$ was modeled as a Hertzian contact [5].

The Vignole rail profile UIC 60 (NF A 45-317) was considered in this simulation $[5,6,7,8,9]$.

From the observations of defects, we modeled the following cases:

- Defects of adhesion simulated by the existence of some form (do not form sharp angles) being located at the rail/weld interface in the central zone level of rail foot (figure 3a).

- Defects of porosity simulated by the existence of an abundance of spherical cavities $(D=3 \mathrm{~mm})$ in the weld zone (figure 3b) [5];

Subsequently, the Hertzian average pressure (505Mpa) was considered in this study.

From this simulation, we have simulated by the finite element method, the mechanical behavior of the rail subjected to Hertzian loading using 505MPa. In addition to loading, we considered the thermomechanical residual stress by a change in temperature $\left(\Delta \mathrm{T}=\mathrm{T}_{\text {ref }}-\mathrm{T}_{\text {Fusion }}\right)$ with $\mathrm{T}_{\text {ref }}=20^{\circ} \mathrm{C}$ (reference temperature) and $\mathrm{T}_{\text {Fusion }}=600^{\circ} \mathrm{C}$ (temperature of the rails during the melting of filler metal) [5-10]. A portion of the rail $600 \mathrm{~mm}$ long was considered (figure $2 \mathrm{a}$ ). This portion includes the welding

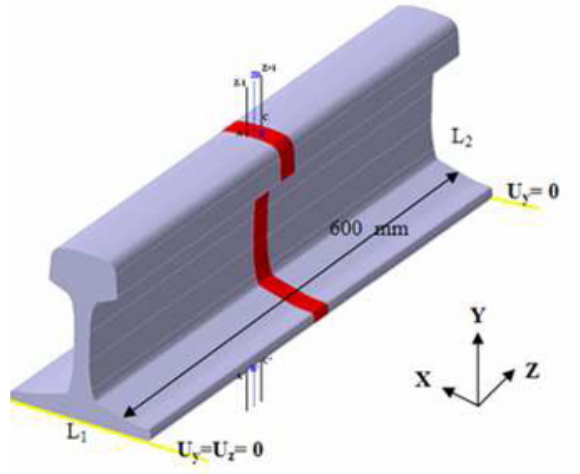

(a)

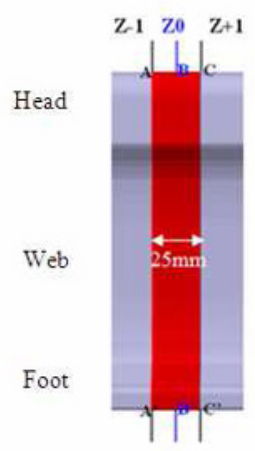

(b)
Fig. 2. (a) Geometric model and boundary conditions of a portion of the rail with a weld seam. (b) Featured in the plane $(\mathrm{Y}, \mathrm{Z})$ the rail/weld interface $(\mathrm{Z}+1$ and $\mathrm{Z}-1)$ compared to the central axis $(\mathrm{Z} 0)$ of the weld zone between the limited positions $(\mathrm{Z}-1)$ and $(\mathrm{Z}+1)$ as we have shown in figure $2 \mathrm{a}$. The width of this zone is taken equal to $25 \mathrm{~mm}$ (figure $2 \mathrm{~b}$ ).

The boundary conditions we have taken into account are: displacement along $\mathrm{Y}$ and $\mathrm{Z}$ are zero on the line (L1) and only the displacement along $\mathrm{Y}$ which is zero on the line (L2) (figure 2a). In this simulation, we have considered two configurations associated with the two defects mentioned above. In the first configuration, we have equated the defect of adhesion in a recess in the field located in the central zone of rail foot (figure 3a). The geometric shape of this recess was determined from observations (figure 1a). In the second configuration, the defect of porosity, was represented by spherical cavities (Ø $3 \mathrm{~mm})$, distributed throughout the volume of the weld zone (figure $3 b$ ).

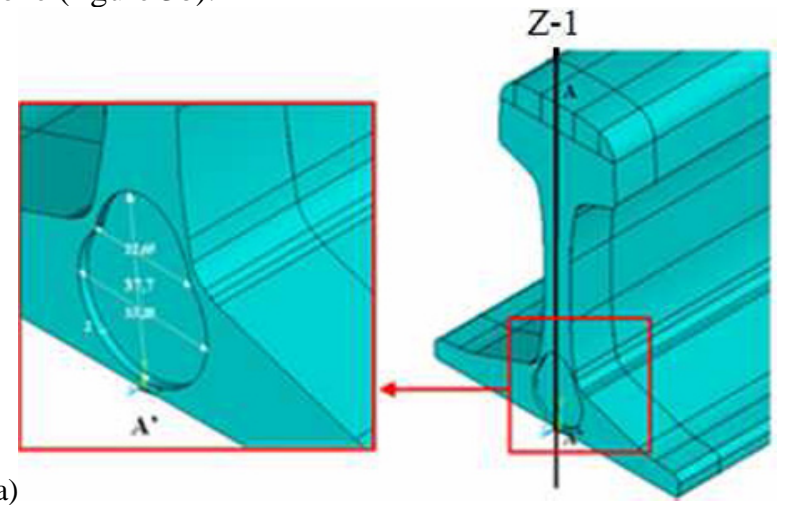

(a)

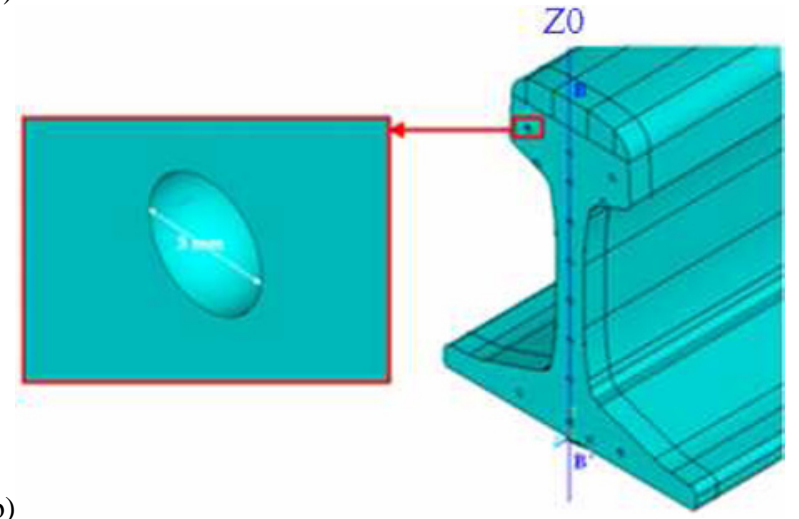

Fig. 3. (a) Models of adhesion defect and (b) porosity defect

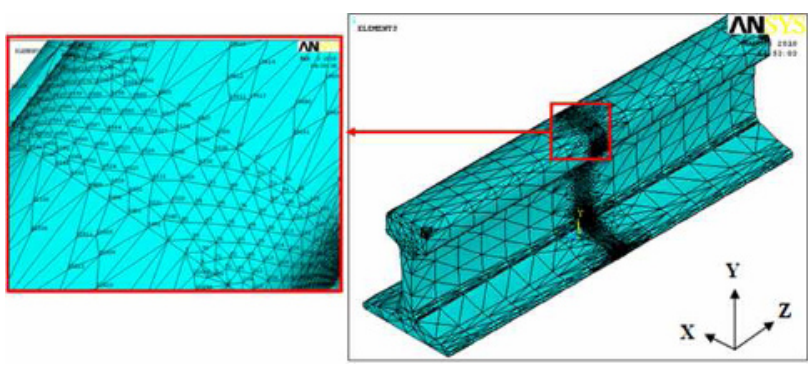

Fig. 4. Meshing of the structure studied by elementary volume type SOLID 185 (ANSYS)

Both configurations were meshed with solid elements SOLID 185 type using the computer code ANSYS (figure 4). For the mesh of the structure and particularly at the weld junction, until the solution no longer changes in stress as a function of its size. The number of elements considered is 30,000 , of which $50 \%$ was attributed to the junction zone of welding [5]. Indeed, the mesh 
refinement at this particular zone we will develop our analysis from accurate results. The material considered is steel with the Young's modulus as $200 \mathrm{GPa}$ for the rail and $243 \mathrm{GPa}$ for the weld. The Poisson's ratio is taken equal to 0.3 .

\section{Microscopic analysis}

The micrographic analysis was performed on the base metal (figure 6) and the filler metal of a thermite weld affected by the defect of adhesion to the level of web/foot region of the rail (figure 7); Specimens of 90x20 mm² with a thermite weld at the edge were taken from a beam rail $600 \mathrm{~mm}$ in length containing a weld with the defect of adhesion. They are ground, polished and attacked by

\section{On the line Z-1}

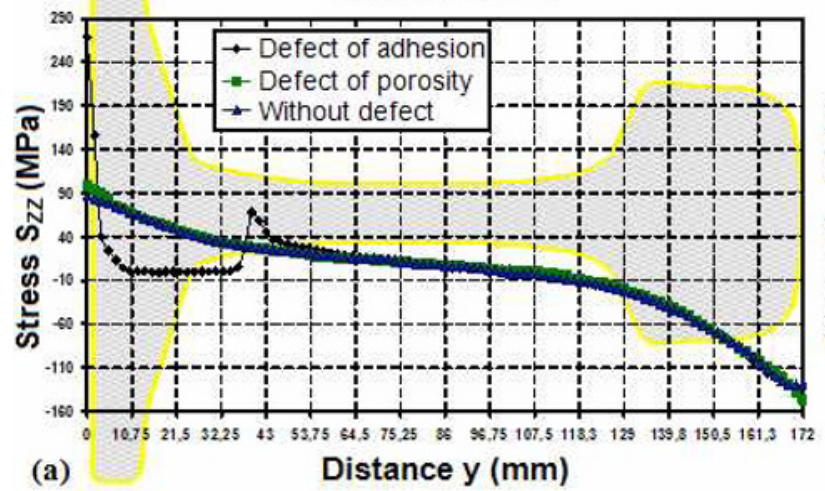

On the line Z-1

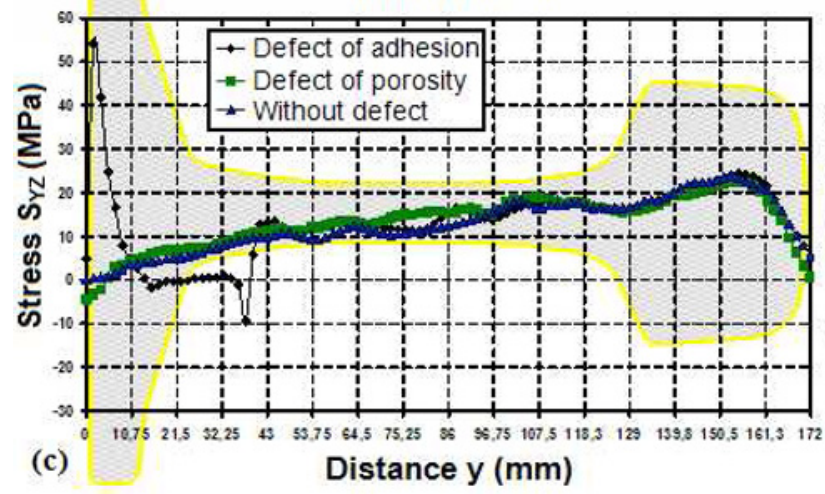

Nital (96\% solution of ethanol and $4 \%$ nitric acid) during 60 seconds and then observed by electron microscopy (SEM).

\section{Results and discussions}

\subsection{Modeling}

Through the simulation of the studied structure (portion of the rail in figure 2), we have sought to highlight the stress field developed from an average load.

In view of the loading and boundary conditions considered, the behavior of this portion of the rail is that of a bending beam in the plane (Y, Z). This bending
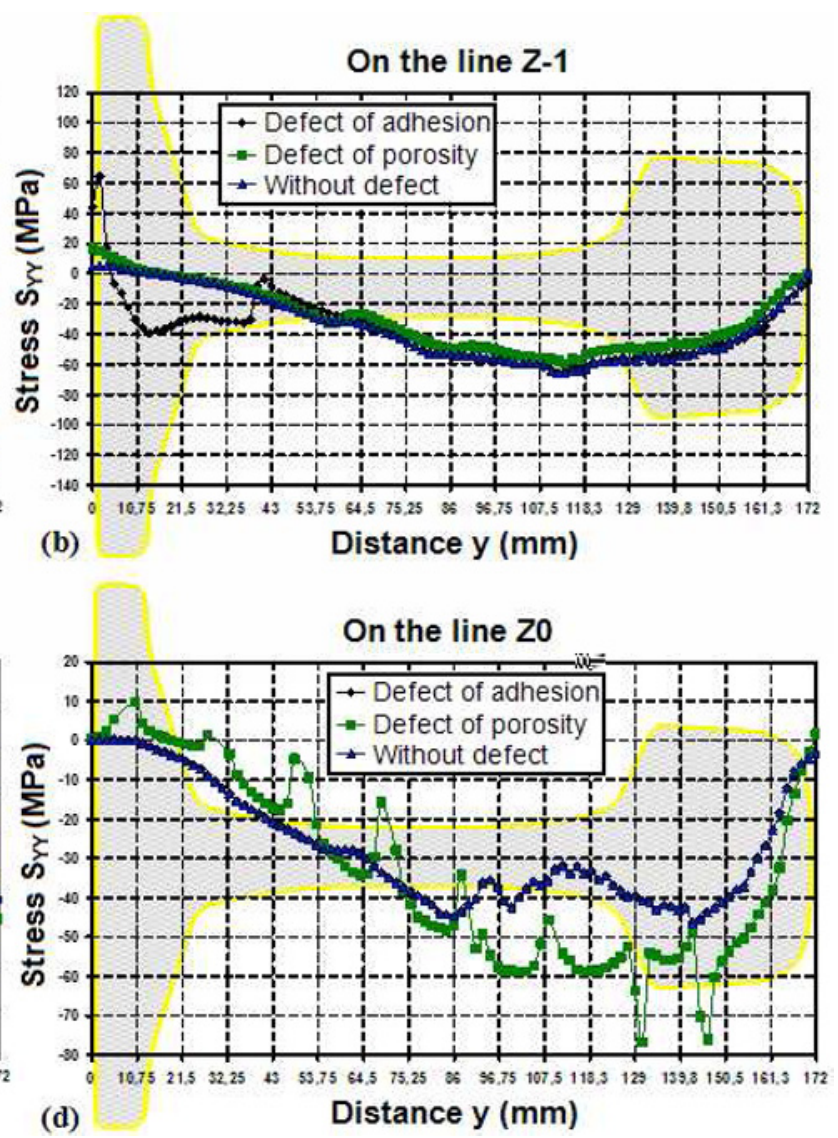

(d)

Fig. 5. Distribution of normal stress bending (a) $S_{Z Z}$, (b) $S_{Y Y}$, (c) $S_{Y Z}$ according to the distance $y$ along the vertical Z-1 and $S_{Y Y}$ according to the distance $y$ along the vertical $\mathrm{Z} 0$

generates a bending stress $\mathrm{S}_{\mathrm{ZZ}}$, a compressive stress $\mathrm{S}_{\mathrm{YY}}$ and a shear stress due to shear effort $\mathrm{S}_{\mathrm{YZ}}$.

For analyze these stresses, we distinguish three scenarios. The first case is that of the structure without defects. The second and third cases correspond to structures that include, the defect of adhesion and defect of porosity.

Results of this comparison between $S_{Z Z}, S_{Y Y}$ and $S_{Y Z}$ were presented in the figure 5. According to these results, we can see that the adhesion defect has generated a local disruption of stress fields. Indeed, at the edges of this defect, the peaks have been developed for all components. The maximum of these peaks was obtained for the component $\mathrm{S}_{\mathrm{ZZ}}$ near the free surface of the rail foot and it is about $290 \mathrm{MPa}$. For the porosity defect, disturbances of the stress field were not significant. Only changes in the component $S_{Y Y}$ was characterized by small localized peaks and whose level is generally low (figure $5 d)$.

\subsection{SEM examination of specimens}

Microstructural observations were carried out in a scanning electron microscope on two specimens of rail [base metal (figure 6) and filler metal of a weld affected by the adhesion defect (figure 7)]. These specimens are attacked by Nital to facilitate comparison of observations results of the grain size.

According to observations by SEM, shown in figures 6 and 7 , two successive zones were distinguished: a zone with a large grain structure (figure 7) and one structured 


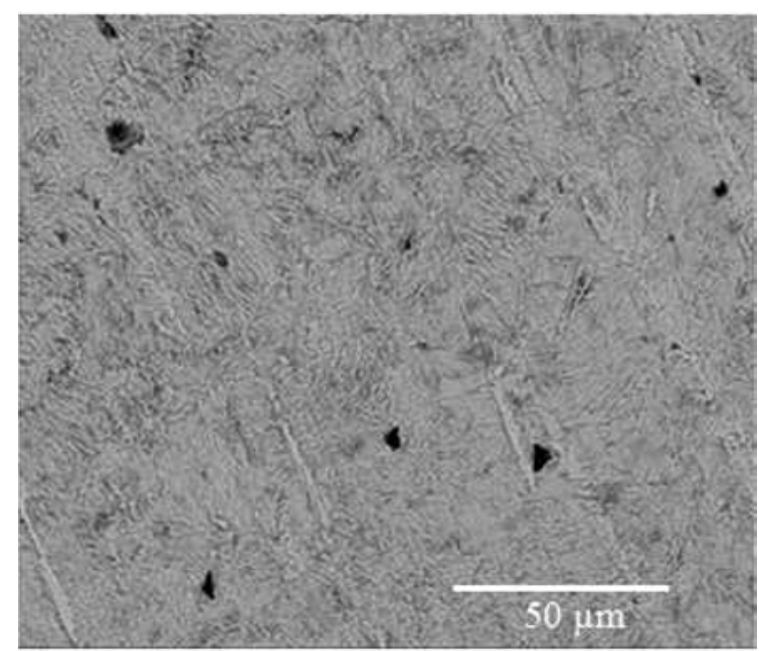

Fig. 6. Scanning electron microphotograph analysis of the base metal specimen etched by Nital

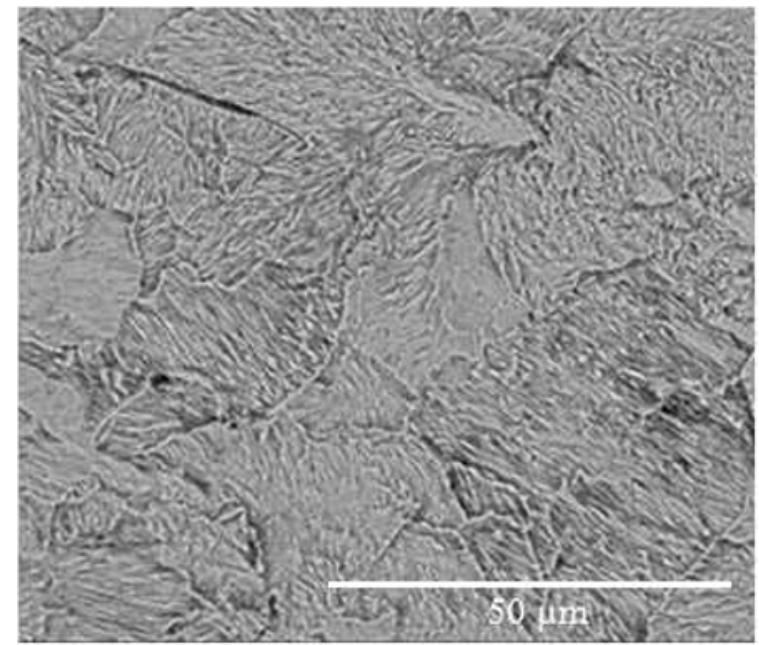

Fig. 7. Scanning electron microphotograph analysis of the filler metal specimen etched by Nital

by small grains (figure 6). Indeed, after preheating the rail ends, the temperature is not uniform because of the imperfect reaction in the joint to be welded. The minimum temperature was located in the central zone of rail foot. When casting into the joint to be welded, the solidification begins with a rapid germination of the solid metal in the central zone of rail foot. This rapid solidification can generate poor bonding (adhesion defect) and keep a large grain structure compared to that of base metal (figure 7). Therefore, the solder becomes more brittle in the central zone of rail foot. This local embrittlement can cause brittle fracture of thermite welds.

\section{Conclusion}

The modeling results we obtained clearly show that it is the defects of adhesion which tend to concentrate more stresses. In addition, they are usually located at the rail/weld interface, the zone where high residual shear stresses are developed.

These particular defects that our attention to further our modeling, appears to be from a bad preheating. Indeed, these defects observed at the central zone level of rail foot are in the form of black spot (excess carbon). This can be explained by a lack of oxygen during preheat the ends of the rail which is always located in remote zones to the source of preheating. This lack of oxygen would cause an imperfect combustion local reaction; therefore the local temperature in the zone would not achieve the desired value.

The microscopic results clearly show the appearance of the local embrittlement phenomenon (due to the formation of large grains in the central zone of rail foot) in the central zone level of rail foot at the rail/weld interface. This phenomenon may facilitate the crack propagation at points of stresses concentration of adhesion defect (see figure 5) and eventually can lead to brittle fracture at the rail/weld interface.

\section{References}

1. Thermit Welding, Thermit Australia Pty Ltd, The SkV-F process.

2. P.-J. Mutton, E.-F. Alvarez, Failure modes in aluminothermic rail welds under high axle load conditions, Engineering Failure Analysis 11, 151166 (2004).

3. R. Moller, P. Mutton, M. Steinhorst, Improving the performance of aluminothermic rail welding technology, through selective alloying of the rail head, Proc. $7^{\text {th }}$ International Heavy Haul Conference, Brisbane, 331-338 (2001).

4. Bureau d'Enquêtes sur les Accidents de Transport Terrestre, BEA-TT, Rapport d'enquête technique sur le déraillement du train 5941 survenu le 25 février 2006 à Saint Flour 15, 20-21 (2006).

5. I. Mouallif, A. Chouaf, A. Elamri, A. Benali, Effets des défauts de soudure aluminothermique sur le comportement mécanique des rails, Revue de Mécanique \& Industries (EDP Sciences) 12, 343-351 (2011).

6. I. Mouallif, A. Elamri, A. Chouaf, A. Benali, Étude $\mathrm{du}$ comportement des rails soudés par aluminothermie, $3^{\text {ème }}$ Congrès International Conception et Modélisation des Systèmes Mécanique CMSM'2009, Hammamet, Tunisie (2009).

7. I. Mouallif, A. Elamri, A. Chouaf, A. Benali, Étude du comportement mécanique des rails soudés par aluminothermie, $9^{\text {ème }}$ Congrès de Mécanique, Marrakech, Maroc (2009).

8. I. Mouallif, A. Benali, A. Elamri, A. Chouaf, Étude $\mathrm{du}$ comportement des rails soudés par aluminothermie, Congrès Algérien de Mécanique CAM'2009, Biskra, Algérie (2009).

9. NF A 45-317 Produits Sidérurgiques Laminés à Chaud, Rail Vignole type $60 \mathrm{~kg} / \mathrm{m}$ et éclisse, Profil: caractéristiques et tolérance.

10. I. Mouallif, A. Chouaf, A. Elamri, A. Benali, Étude du comportement mécanique des rails soudés par aluminothermie, VI ème Journées d'Études Techniques Marrakech, Maroc (2010). 